nd International Conference Art, Illustration and Visual Culture in Infant and Primary Education

\title{
The interactive educational printed book: plaything or polymath?
}

Jemma Westing jemmawesting@msn.com

Dorling Kindersley, United Kingdom

Reference

Westing, Jemma; (2012) "The interactive educational printed book: plaything or polymath?", p. 316-320 . In: Barbosa, Helena; Quental, Joana [Eds]. Proceedings of the 2nd International Conference of Art, Illustration and Visual Culture in Infant and Primary Education. São Paulo: Blucher, 2015

ISSN 2318-695X, ISBN: 978-989-98185-0-7

DOI 10.5151/edupro-aivcipe-60

Abstract

I am arguing that interactive visual reference printed books for children are polymathical because they facilitate deep learning which accretes in unison with semiotic trends in the creative and media industries. Interactive books therefore transcend their 'novelty' value by becoming deep and meaningful pedagogic tools. Active learning is promoted through direct, physical environments that showcase information kinaesthetically and which foster creativity, interaction and the retention of knowledge whilst providing a timeless, polycentric entertainment spectacle. Interactive printed books can present literary material in similar semiological ways to current techno-literacy content in popular digital culture. These similarities modernize literary material in the printed books and may be a contributing factor with regards the interactive printed book's growing popularity.

Keywords book design, interactive, polymath, children, learning

\section{Introduction}

I work as an interactive children's book designer for award winning reference publishers Dorling Kindersley. My responsibility is to bring traditional lexigraphic reference material to life in the most innovative way possible. All the work I have produced and am currently producing has been specifically designed to culminate in paper-based, printed books.

The Interactive book (in printed form) is an umbrella term used in this paper to define a printed book containing paper engineered mechanisms, all of which perform in a different manner. These types of books are commonly referred to as pop-up books or novelty books. As visual reference packages for children, the books and their engineered components are designed and sculpted often in a 3 rd dimension to enhance the text or subject of a book in a theatrical manner. The majority of these books are essentially pictorial and mechanical in nature and the designs themselves do not function without reader participation: the reader is often required to fully open a spread to activate a pop-up, turn a disc, pull a tab, or lift a flap in order to solve a problem.

Interactive books or 'movable books' were born out of a need to problem solve, and initially were used as tools for a sophisticated audience who needed to organize and simplify a research process. Children are the primary audience for my case study in this paper but they are by no means unsophisticated. The success of an interactive book is measured by its ability to fully engage a child and show consideration for the child's perspective, the place of gaze, physical reader input and output and, how well the manipulation of paper mechanisms enhance and illustrate the changes and transformations within the text subject and the reading subject-for the purpose of long term knowledge retention. 
2nd International Conference

Art, Illustration and Visual Culture in Infant and Primary Education $2^{\circ}$ Congreso Internaciona

Arte, Ilustración y Cultura Visual en Educación Infantil y Primaria
Congresso Internacional

de Arte, Ilustração e Cultura Visual

na Educação Infantil e Primária

\section{The case study-'Optical Illusions'}

The availability of interactive books signifies that they are a proven way of getting information through to children. Prior to this paper, I researched the ways in which interactive books respond to the present day niche for multiple perspective entertainment. I apply those findings in my day to day practice but have since realized that there is a far greater, underrated epistemological value to interactive books.

Optical Illusions is my most recent interactive book project and the subject is, as the title suggests. Optical Illusions are vibrant, intrusively perceived images that differ from objective reality: the effect that they have on your brain causes you to perceive something which does not match the physical extent of the initial image in front of you; the reader is offered a visual magic which intrinsically motivates them to seek the knowledge behind it. The illusions combine art and science together and are visually satisfying, demographic problems that anyone can enjoy trying to solve; the publishing market responded positively to the concept. Contextually, it seemed an appropriate subject for current market trends: illusions explore a theme of boundary traversal where fiction and reality appear to merge. This same theme permeates through the current content that dominates the applications on our children's mobile phones, computer software, ipad apps and video games. All of the content on these devices promise to deliver an illusory experience which allow the child to experience a virtual reality where in some cases, their whole sensorium engages in an immersive first person viewpoint where objects and context are arrayed in all three spatial dimensions which the child can then navigate. Determining what is objective reality when looking at illusions is hard enough when the images are printed flat onto the page. However, some contemporary examples take the theme to new dimensional extremes and require kinetic reader input in order to function properly. I felt that in order to effectively communicate the full scope of the subject, the book would have to represent all illusion types taking into account the dimensions and how design conditions as a whole would effect visceral reaction within the reader. I felt turning the book into an interactive concept would put me the designer, in a far better position to best represent my subject matter.
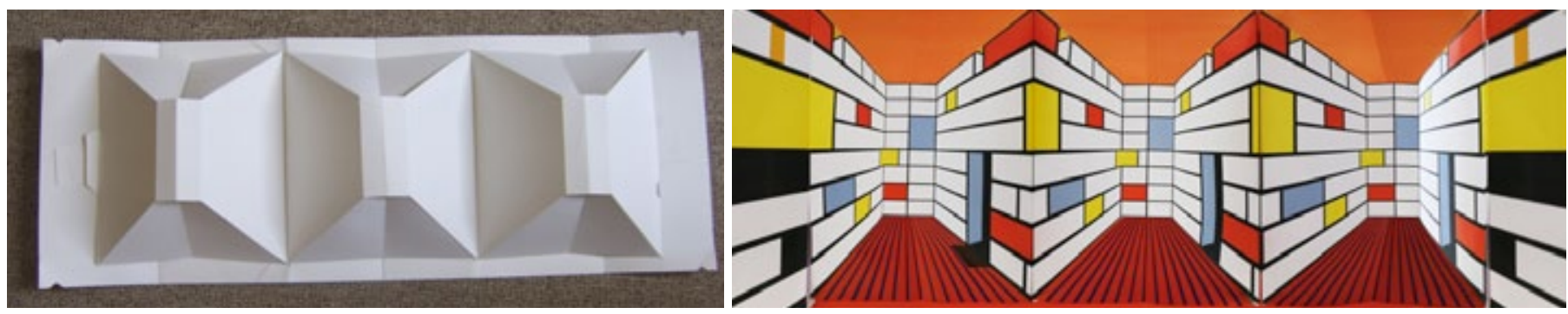

Figures 1 and 2. On the left: Dorling Kindersley Optical Illusions: "Build your own sculpture" working white (July, 2012). Source: personal. On the right: Dorling Kindersley Optical Illusions: "Build your own sculpture" artwork test (July, 2012) Source: personal.
The Optical illusions book covers 50 different kinds of illusions, most of which are magnified as development indicated that presenting them in large format provided much better spectacle, and visceral reader reaction. Some Illusions are simply flat printed whereas others are broken down with the aid of mechanical devices to aid reader analysis, synthesis, problem solving and evaluation. Two illusions in particular have been developed as physical structures. The centre of the book houses a spinning thaumatrope which gives the effect that the two images on either side of the disc are seen to merge. The reader needs to hold the book closely and then open and close it very quickly in order to see the effect. The second sculpture folds out into the finale: a 3D panoramic scene which defies the rules of perspective when viewed at a distance. My research in conjunction with a visit to Patrick Hughes the renowned 3D perspective artist, indicated that this 3D structure had never been constructed in book format before. The examples he had made me determined to push the book's bibliographic boundaries to make it work.

Once assembled and positioned upright, the effect is that when you walk past the sculpture, the walls follow your gaze. It has the ability to capture more than one persons' eye at a time, transforming the content and experience into a shared group activity. 
2nd International Conference Art, Illustration and Visual Culture in Infant and Primary Education $2^{\circ}$ Congreso Internacional

A en Educación Infantil y Primaria
(1)

de Arte, llustracão e Cultura Visual

na Educação Infantil e Primária

\section{The printed polymath and its polycentric value.}

Readers of the Optical Illusions book are intrinsically motivated to test and solve the visual problems with the use of interactive mechanisms: the reader has to analyse, synthesize and problem solve, whilst thinking in a cognitively descriptive manner in order to achieve long-term understanding of the subject. The book is not designed to provide the reader with tacit or passive acceptance of information nor the rote memorization of isolated and unlinked facts. The reader has to actively participate in order to further test and evaluate the knowledge.

The challenge of distinguishing between perceptions and objective reality in Optical Illusions is presented and experienced as interactive game-play: readers who look at the pop-up panoramic scene (fig 2) walk towards it in the hope that at some point along the way, their eyes will see past the perception and they'll see truth; some readers try to walk past it slowly, seeking the moment where their eyes detect the real sculptural dimensions of the pop-up. Many find themselves having to walk right up to the sculpture and physically touch the point which they perceive to be in the distance in order to believe that it is actually in the foreground. This playfulness leads to cognitive thinking: the reader is self aware and tries to distinguish between what they perceive to be illusion and reality. This cognition is achieved with the aid of applied engineered mechanisms and so these tools become valuable. However, in the Pacific Standard Magazine in August 2010, psychologist Judy Loache said that "Children's Pop-Up Books Flop as Learning Tools". She declared with reference to earlier research made by the University of Virginia that when children "have been encouraged to manipulate and play with something, it becomes harder for them to grasp the fact that object is actually a symbol of something else (ie: picture of a parrot)."(Tare \& Gelman 2010) She added that the children become more focused on the objects they're manipulating and are less concerned with what it's supposed to represent, further suggesting that manipulating flaps, pull-tabs etc "might have increased their cognitive load such that they could not additionally process what the adult was saying about the content of the book..." Her conclusion was that if the book didn't have so many "distracting elements, and had more detailed images, learning labels and facts from the realistic book may have been an easier task." (Tare \& Gelman 2010) Two months later, the article was contested by author and interactive book designer Sally Blakemore, who strongly criticised the research for being flawed at the start because attention was paid to research and results which were highly unsound, predominantly by 'age inappropriateness' (Blakemore, 2010) and by the lack of experimental controls: it was not clear as to whether the researchers were using flap books or pop-up books, or both. This is important because flap books as Blakemore suggests are:

Within a toddlers' range of discovery, more complicated pop-up structures on the other hand evade their conceptual understanding particularly if the focus is on "labelling a recognizeable image" within a complicated pop-up (...). (Blakemore, 2010).

Loache concluded in the original article that "while pop-up books 'may have their place as entertainment,' their 'bells and whistles' approach appears to be counterproductive to learning..."(Tare \& Gelman 2010)...which gives the impression that pop-up books were used instead of the more age-appropriate flap-books. These flaws in this article are important to consider because having awareness of age appropriateness and an informed knowledge of the application, constraints and characteristics of interactive devices, will help to determine as to whether or not the final interactive book will transcend its hypothetical novelty status through its performance. I use the word hypothetical because through my experience in publishing, any interactive project concept which successfully finds a place on a publishing programme is automatically classed as a 'novelty' or as a 'gift' book. Interactive books do tend to have thicker spines and formats that are 'novel' in comparison to similar subject books on a book shelf. However, I feel that classing the entire book as 'novelty' or 'gift' is detrimental to the value of the educational content inside. A 'novelty' classification implies a celebration of entertainment: implying that it is a book for superficial surface learning which has originated from subordinate learning objectives, rationales and outcomes in terms of teaching credibility. 
2nd International Conference Art, Illustration and Visual Culture in Infant and Primary Education $2^{\circ}$ Congreso Internacional

Arte, llustración y Cultura Visual en Educación Infantil y Primaria $2^{\circ}$ Congresso Internacional

de Arte, llustracão e Cultura Visual

na Educação Infantil e Primária

\section{Conclusion}

Interactive printed books have the potential to achieve polymathic status early on in the books conceptual stage and this is determined by how well the design team considers context and audience: children as a 21st century sophisticated audience have high expectations of the multi-modal content available to them generally; the entertainment value of which (measured by levels of sensory interactivity for the individual and/or group, the polycentric narratives, and how much the child can manage and direct their own experiences) is highly regarded. Through the promotion of play, interactive books have the valuable aptitude to take into account the 'funds of knowledge' (Lopez, Learn NC) of 21st century learners and can meet the expectations for sophisticated entertainment and varied learning in printed capacity. Design teams must consider this; lexigraphic layouts (both on spread and devices) will determine the level of polycentric narration and the design of the interactive elements will determine levels of sensory engagement and reader directorship; the two pop-up structures in Optical Illusions provide opportunities for both individual and group experiences.

Further value to interactive books lie within their capability to host exciting collaborations both through subject matter, and between content and reader: Optical Illusions for example, bridges artistic and scientific knowledge together through new dimensional conditions which further impact on the reader as the new conditions intensify visceral reactions as the problems to solve become much more challenging. Distinguishing between perception and reality is now much harder as the problems that need solving now present themselves in a real, physical, 3D capacity: the panoramic scene can be gazed at from many angles and despite the fact that the reader is all too aware of its true structural formation (they followed instructions to put it together), the effects still defy perspective and imply magic, leaving the learner intrinsically motivated to monitor, enquire, and self-question. By immersing themselves in the design, readers are transformed into active collaborators with the book whose involvement is divided as

"part designer and part performer: part performer because it is the reader's kinetic energy which creates the movement to bring the piece to life, and part designer because the reader's imagination, common sense and reading ability are needed for the design to reach its full potential." (Avella, 2009:8)

The novelty status of a printed interactive book should be contested but on defined grounds: those being of whether or not the interactive book in its entirety can help a child engage in cognitive thinking; those that can, become pedagogical tools for deep learning; those that cannot would warrant the 'novelty' status whose capacity goes as far as the entertaining 'bells and whistles' (Tare \& Gelman 2010) built inside. To expand, if a visual reference publication for children includes interactive devices such as pop-up structures and lift-the-flaps for educationally unjustified purposes i.e. to hide additional text; the interactive mechanisms turn from useful tools into 'distracting elements' whose educational scope will demand the use of lower order cognitive skills (basic knowledge and comprehension) resulting in trivial knowledge retention only.

As physical kinaesthetic artefacts, interactive printed books could be the 21st century's publishing solution to modernizing printed paper-based content in the classroom because they bridge the gap between traditional and digital reading formats. Their existence highlights the constructive similarities between paper and techno-literacies rather then the differences. Moving forward, this should help soften the fears of educators who understand that the curriculum needs modernizing and yet are worried that rejuvenating or redefining it (and its tools) will mean embracing "anything digital at the cost of critical thinking and of values associated with print literature and literacy." (Beavis 2002: 47) An interactive printed book, whose choreographed mechanical components have been applied with defined educational purpose and rationale, will provide a child with an opportunity to engage in deep learning.

Relevant to 21st century industry context, interactive printed books can achieve polymathic status as educational tools if their capacity to facilitate active, deep learning and cognitive thinking is capitalized on. The reader will use cognitive skills in order to achieve long term subject understanding. If the final book outcome achieves this in totality, then it certainly is not superficial or novel in value. 
$2^{\text {nd }}$ International Conference Art, Illustration and Visual Culture in Infant and Primary Education $2^{\circ}$ Congreso Internacional
Congresso Internacional

de Arte, llustração e Cultura Visual

na Educação Infantil e Primária

\section{Bibliographical references}

Avella, N. (2009). Paper Engineering: 3-D design techniques for a 2-D material. Rotovision, pp78.

Beavis, C. (2002). Reading, Writing and Role-Playing Computer games. In silicon Literacies, Communication, Innovation and Education in the Electronic Age. pp 47-61) Routledge, London Blakemore, S (2010) Pop-Up Books: More, in Fact, Is More. Pacific Standard Magazine.

Lopez, K, J. Funds of Knowledge. Learn NC-program The University of North Carolina at Chapel Hill School of Education.

Tare, M\& Gelman S (2010) Less is More: How manipulative features affect children's learning from picture books. Journal of applied developmental psychology: University of Virginia. 